\title{
Does Sunspot Numbers Cause Global Temperatures? Evidence from a Frequency Domain Causality Test
}

\author{
Rangan Gupta ${ }^{1}$, Luis A. Gil-Alana ${ }^{2}$ and OlaOluwa S. Yaya ${ }^{3}$ \\ ${ }^{1}$ Corresponding author. Department of Economics, University of Pretoria, Pretoria, 0002, South \\ Africa. Email: rangan.gupta@ up.ac.za. ${ }^{2}$ Universidad de Navarra, Faculty of Economics, Pamplona, \\ Navarra, Spain. Email: alana@unav.es. The author gratefully acknowledges financial support from \\ the Ministry of Economy of Spain (ECO2011-2014 ECON Y FINANZAS, Spain). \\ ${ }^{3}$ Faculty of Science, University of Ibadan, Ibadan, Nigeria. Email: os.yaya @ mail.ui.edu.ng. The \\ author gratefully acknowledges $2009 \mathrm{PhD}$ research grant from the Federal Government of Nigeria \\ through National University Commission.
}

\begin{abstract}
This paper applies the causality test in the frequency domain, developed by Breitung and Candelon (2006), to analyze whether sunspot numbers (used as a partial approximation to solar irradiance) cause global temperatures, using monthly data covering the time period 1880:1-2013:9. While, standard time domain Granger causality test fails to reject the null hypothesis that sunspot numbers does not cause global temperatures for both full and sub-samples (identified based on tests of structural breaks), the frequency domain causality test detects predictability for both the full-sample and the last sub-sample at short (2 to 2.6 months) and long (10.3 months and above) cycle lengths respectively. Our results highlight the importance of analyzing causality using the frequency domain test, which, unlike the time domain Granger causality test, allows us to decompose causality by different time horizons, and hence, could detect predictability at certain cycle lengths even when the time domain causality test might fail to pick up any causality. Further, given the wide-spread discussion in the literature, that results for the full-sample causality, irrespective of whether it is in time or frequency domains, cannot be relied upon when there are structural breaks present, and one needs to draw inference regarding causality from the sub-samples, we can conclude that there has been an emergence of causality running from sunspot numbers to global temperatures only recently at cycle length of 10.3 months and above.
\end{abstract}

Keywords: Causality; frequency domain; global temperatures predictability; sunspot numbers JEL classification: $\mathrm{C} 32$

\footnotetext{
* We would like to thank an anonymous referee for many helpful comments. Any remaining errors are, however, solely ours.
} 


\section{Introduction}

The Granger causality testing procedure (Granger, 1969) is being extended beyond macroeconomic time series modeling. In other areas like climatology, there are time series variables expected to cause each other, and Vector Autoregressive (VAR) or Vector Error Correction (VEC) models are used to find empirical evidence of possible causality between the variables concerned. This paper attempts to find whether sunspot numbers, used as an approximate proxy for the solar activity, have predictive content for global temperatures using the frequency domain causality test proposed by Breitung and Candelon (2006). Intuitively (and as also seen from our results), we would expect the causal relationship to run in one direction only from sunspot numbers to global temperatures. ${ }^{1}$

To say that the existing literature on causality in the time domain is huge, would probably be an understatement, and a review of this literature is beyond the scope and focus of this paper. The Granger causality test in the time domain cannot decompose causality at different frequencies, and hence provides us with additional information, as to whether the causality is in the short-, medium or long-runs. This approach is likely to pick up causality, when the standard time-domain Granger causality test might not (something we show below as well), and hence, is more informative to not only the academician, but also a policy maker, especially when policy questions are involved. This follows from the observation in Breitung and Candelon (2006, p. 376): "In stationary systems the concept of long-run causality is not as obvious. Assume that the $x_{t}$ is predicted using only the past of the series, $x_{t-1}, x_{t-2}, \ldots$ If the spectral density of the resulting forecasting error at low frequencies can be explained by the additional past information of $y_{t}$, then $y_{t}$ is said to be a long run cause for $x_{t}$. Although, in a stationary framework there exists no long-run relationship between time series, a series may nevertheless explain future low frequency variation of another time series. Consequently, our concept does not postulate that a variable $y_{t}$ affects another variable $x_{t}$ at a infinite time horizon. Rather, causality at low frequencies implies that the additional variable is able to forecast the low

\footnotetext{
${ }^{1}$ The null hypothesis that global temperatures cause sunspot numbers is overwhelmingly rejected based on both the time domain and frequency domain causality tests. These results are available upon request from the authors.
} 
frequency component of the variable of interest one period ahead. This is an important conceptual difference to the approach suggested by Dufour and Renault (1998, 2006).”. Frequency domain approaches to causality were suggested and applied in Granger (1969), Geweke (1982), Hosoya (1991) and Yao and Hosoya (2000). Geweke (1982) and Hosoya (1991) applied the spectral density function, while Yao and Hosoya (2000) used a Wald-type test procedure for causality at some given frequency, based on non-linear restrictions of the autoregressive (AR) parameters. Breitung and Candelon (2006) used the VAR model in the frequency domain to test for causality between the time series variables. More recent applications of the causality test are found in Assenmacher-Wesche et al. (2008), Bodart and Candelon (2009), Gronwald (2009), Schreiber (2009), Tari and Abasiz (2009), Ciner (2011a,b), Gradojevic (2013), and Wei (2013a, b). Wei (2013b) investigates the dynamic relationships between oil prices and the Japanese economy based on the frequency domain perspectives of Breitung and Candelon (2006) and Ashley and Verbrugge (2009), and the latter method detected non-linear relationships between oil price and other independent macroeconomic variables. From these non-linear relationships, the linkages between oil prices and unemployment rates were mainly detected at the high frequencies.

Causality has been analyzed in extensively in both time and frequency approaches. For example in Gil-Alana (2004) and Bentzen (2007) to investigate possible relationships between oil price and other macroeconomic variables. Sun and Wang (1996) applied both approaches to confirm the dynamic relationship between global surface temperature and carbon dioxide $\left(\mathrm{CO}_{2}\right)$. Generally, in applied economics, we have the accounts of Auerbach and Rutner (1976); Jones and Uri (1987); Erol and Balkan (1991); Dropsy (1996); Gelper, Lemmens and Croux (2007); Ashley and Ye (2012) and Nachane and Dubey (2013).

The frequency domain causality test of Breitung and Candelon (2006) has been applied in many papers in studying the long and short run relationship between economics variables (see Yanfeng (2002); Bodart and Candelon (2009); Aslanoglu and Deniz (2012), Gradojevic and Dobardzic (2013) and Arouri, Tiwari and Teulon (2014) among others). This present work is the first of its kind applying this methodology 
in studying the relationship between sunspot numbers and global temperatures.This present work was motivated by Gil-Alana, Yaya and Shittu (2014). In the paper, time bivariate causality analysis in the time domain was used to check for possible long run relationship between sunspot numbers and global temperatures, and the results rightly rejected the hypothesis of possible relationships between the variables. Using the same sampled data, this present work is re-designed to investigate in the frequency domain the possible relationship between the variables.

In this paper, we focus on the ability of sunspot numbers to predict future global temperatures using a causality testing procedure in the frequency domain. Nevertheless, we should note that sunspot number records can only be used as an approximate proxy of the solar activity that can eventually influence the climate. In fact, sunspot number record is considered as one of the many ingredients adopted to make proxy models of solar activity, and these proxy models are the ones that are related in many cases with the temperature records. (See, e.g., Friis-Christensen and Lassen, 1991; Hoyt and Schatten, 1997; Wilson, 1997; Eichler et al., 2009; Soon, 2009).Other authors that find significant relationships between solar radiation and global temperatures include Lean and Rind (1998, 2009), Scafetta and West (2003, 2005), Scafetta et al. (2004), Scaffeta (2009, 2011), Folland et al. (2013) and Zhou and Tung (2013). Lean and Rind (2009), for example, argued that as a result of declining solar activity there will be periods with lack of overall working. At a regional level, the relationship between the two variables has been studied by Shindell et al. (2001), Ineson et al. (2011) and others. On the other hand there are some authors claiming that the two variables are unrelated. This includes authors such as Pittock $(1978,1983,2009)$ Love et al. (2011) and others. Usoskin, et al. (2004), using a long span of data of about 1150 years showed that solar activity might be highly correlated with climate. Nevertheless, these authors claim that sunspot numbers cannot explain the warming effect in the temperatures in the last 30 years, whereas they find significant correlation between sunspot number and geomagnetic activity. Thus, there is no consensus about the possibility 
of a relationship between solar irradiance and global temperatures, and a recent review on these issues can be found in Gray et al. (2010).

The difficulties encountered in modelling sunspot numbers and global temperature data are due to the apparent nonstationarity property of the series and the complex dynamic fluctuations in the cycle amplitude of the sunspot number series (Aguirre et al., 2008). As can be seen from the discussion above, these studies have relied on analysis carried out in the time domain. Realizing that the relationship between solar irradiance measured in terms of sunspot numbers and global temperatures might vary across the frequency bands, a time domain analysis is likely to fail in fully capturing the link between these two variables. Against this backdrop, the present study adopts a frequency domain statistical approach to study the dynamic linkage between sunspot numbers and global temperatures. The paper is structured as follows: Section 2 provides a brief outline of the frequency domain causality test, while Section 3 presents the data and empirical results. Finally, Section 4 concludes.

\section{Methodology: The Frequency Domain Causality Test}

\section{The Frequency Domain Causality Test}

Breitung and Candelon (2006) based the frequency domain causality test on the frameworks of Geweke (1982) and Hosoya (1991). The test is presented in a two-dimensional vector time series $Z_{t}=\left(X_{t}, Y_{t}\right)$ observed at time $t=1, \ldots, T$, where $Z_{t}$ is a finite-order VAR process of the form

$$
\Theta(B) Z_{t}=\varepsilon_{t}, \quad t=1,2, \ldots,
$$

where $\Theta(B)=1-\theta_{1} B-\ldots-\theta_{p} B^{p}$ is a $2 \times 2$ lag polynomial with $B^{k} Z_{t}=Z_{t-k}$. The error vector $\varepsilon_{t}$ is a white noise process, with $E\left(\varepsilon_{t}\right)=0$ and $E\left(\varepsilon_{t} \varepsilon_{t}^{\prime}\right)=\Sigma$, where $\Sigma$ is a positive definite variance matrix. The VAR process may include a constant, a trend or dummy variables. The matrix $\Sigma$ is then decomposed as $G^{\prime} G=\Sigma^{-1}$ where $G$ is the lower triangular matrix of the Cholesky decomposition. 
With the assumption that the system is stationary, the moving average (MA) representation of the process is,

$$
\mathrm{Z}_{\mathrm{t}}=\Phi(\mathrm{B}) \varepsilon_{\mathrm{t}}=\left(\begin{array}{ll}
\phi_{11}(\mathrm{~B}) & \phi_{12}(\mathrm{~B}) \\
\phi_{21}(\mathrm{~B}) & \phi_{22}(\mathrm{~B})
\end{array}\right)\left(\begin{array}{l}
\varepsilon_{1 \mathrm{t}} \\
\varepsilon_{2 \mathrm{t}}
\end{array}\right)=\left(\begin{array}{ll}
\psi_{11}(\mathrm{~B}) & \psi_{12}(\mathrm{~B}) \\
\psi_{21}(\mathrm{~B}) & \psi_{22}(\mathrm{~B})
\end{array}\right)\left(\begin{array}{l}
\xi_{1 \mathrm{t}} \\
\xi_{2 \mathrm{t}}
\end{array}\right)=\Psi(\mathrm{B}) \xi_{\mathrm{t}}(2)
$$

where $\Psi(\mathrm{B})=\Phi(\mathrm{B}) \mathrm{G}^{-1}$. Then, the spectral density of $\mathrm{X}_{\mathrm{t}}$, as given in Breitung and Candelon (2006), can be expressed as:

$$
\mathrm{f}_{\mathrm{x}}(\omega)=\frac{1}{2 \pi}\left[\left|\psi_{11}\left(\mathrm{e}^{-\mathrm{i} \omega}\right)\right|^{2}+\left|\psi_{12}\left(\mathrm{e}^{-\mathrm{i} \omega}\right)\right|^{2}\right]
$$

Geweke (1982) and Hosoya (1991) suggest using the following measure of causality defined as,

$$
\mathrm{M}_{Y \rightarrow X}(\omega)=\log \left[1+\frac{2 \pi \mathrm{f}_{\mathrm{X}}(\omega)}{\left|\psi_{11}\left(\mathrm{e}^{-\mathrm{i} \omega}\right)\right|^{2}}\right]
$$

Plugging now (3) into (4) gives,

$$
\mathrm{M}_{\mathrm{Y} \rightarrow \mathrm{X}}(\omega)=\log \left[1+\frac{\left|\psi_{12}\left(\mathrm{e}^{-\mathrm{i} \omega}\right)\right|^{2}}{\left|\psi_{11}\left(\mathrm{e}^{-\mathrm{i} \omega}\right)\right|^{2}}\right]
$$

Equation (5) is zero if $\left|\psi_{12}\left(\mathrm{e}^{-\mathrm{i} \omega}\right)\right|^{2}=0$, which implies that $\mathrm{Y}$ does not Granger-cause $\mathrm{X}$ at frequency $\omega$.

The null hypothesis that $\mathrm{Y}$ does not Granger-cause $\mathrm{X}$ at frequency $\omega$ is then given as

$$
\mathrm{H}_{0}: \mathrm{M}_{\mathrm{Y} \rightarrow \mathrm{X}}(\omega)=0 \text {. }
$$

The statistic $M_{Y \rightarrow X}(w)$ is then obtained by replacing $\left|\psi_{11}\left(e^{-i w}\right)\right|$ and $\left|\psi_{12}\left(e^{-i w}\right)\right|$ in (5) by the estimated values obtained from the fitted VAR representation. For further details, see Breitung and Candelon (2006). 


\section{Data and empirical results}

The data are at monthly frequency for global land-ocean temperatures (GT) and sunspot numbers (SS), and covers the period from January 1880 to September 2013, with the start and end-points being based purely on data availability at the time of writing this paper. ${ }^{2}$ The global temperatures were obtained from the National Aeronautics and Space Administration's (NASA), Goddard Institute for Studies (GISS) (http://data.giss.nasa.gov/gistemp), while the sunspot numbers were obtained from the Solar Influences Data Analysis Center (SIDC: http://www.sidc.be/sunspot-data). The data for temperatures are anomalies relative to the base period 1951-1980. Figures 1(a) and 1(b) plot the two variables. As can be seen, the plot of the global temperature seems to be nonstationary, though it could well be trend-stationary, while that of the sunspot looks stationary with a cyclical pattern completed at about 10/11 years.

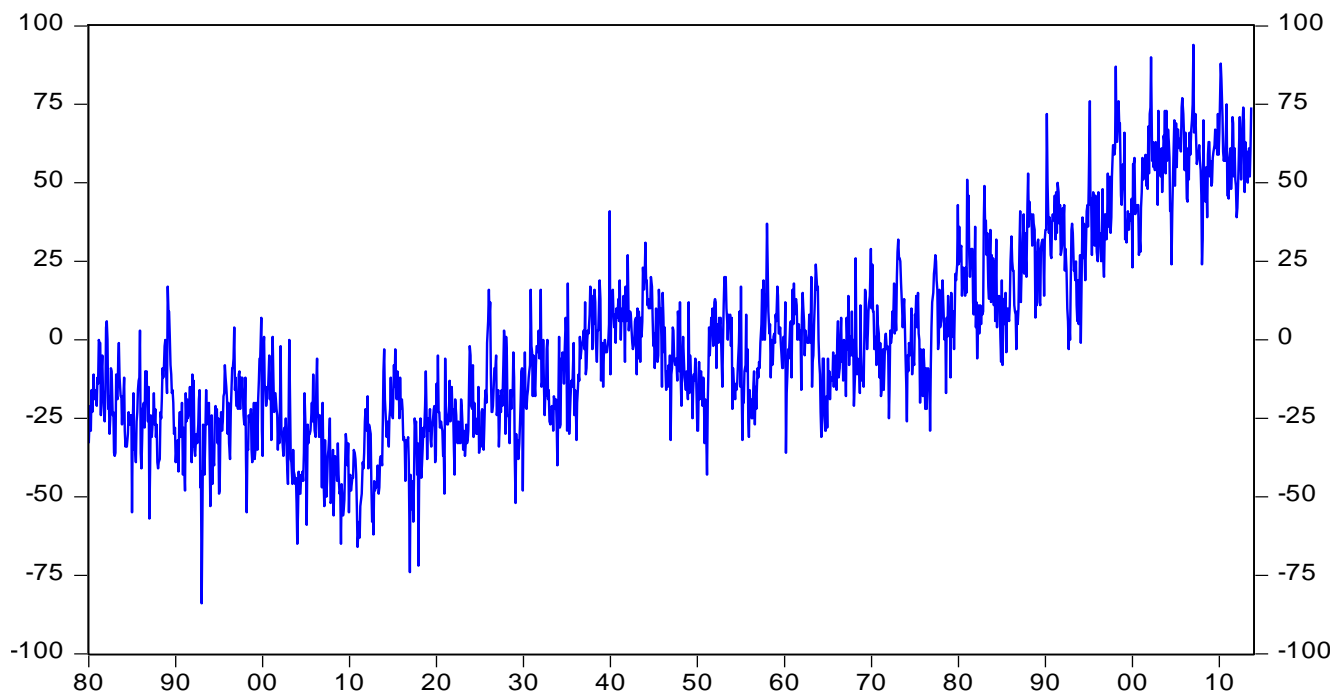

Figure 1(a): Plot of Global Temperatures (1880:1-2013:9)

\footnotetext{
${ }^{2}$ As earlier mentioned, we could alternatively to the sunspot numbers used solar irradiance. Note that the number of sunspots correlates with it over the period (since 1973) when satellite measurements of absolute radiation flux were available. Studies conducted by Vaquero et al. (2006) and Preminger and Walton (2005) reconstruct total solar irradiance from sunspot areas. See also Ambelu et al. (2011) and Scafetta and Willson (2009, 2014) to remark the differences between the sunspot number records and the total solar irradiance records.
} 


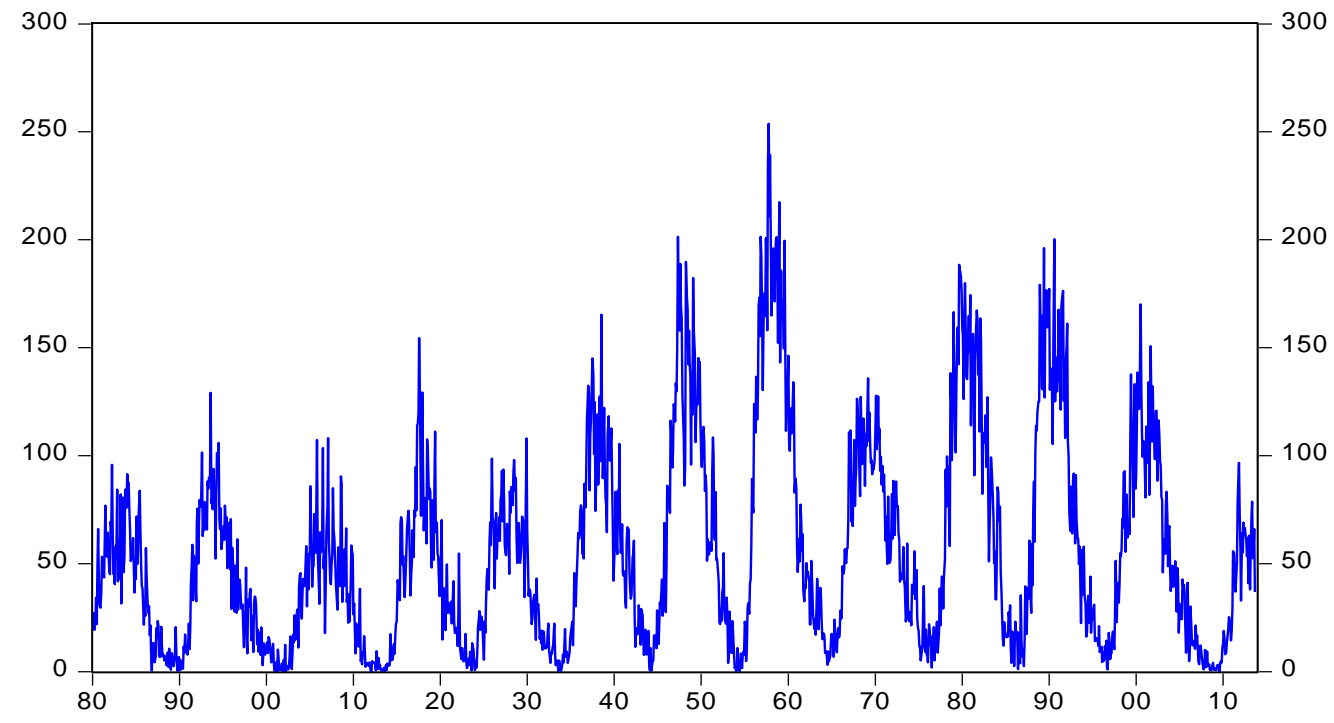

Figure 1(b): Plot of Sunspot Numbers (1880:1-2013:9)

As is standard in time series analysis, we start off with unit root tests to verify whether the two series are stationary, I(0), or not. As can be seen, based on the augmented Dickey-Fuller (1981, ADF), Dickey-Fuller test with Generalised Least Squares detrended residuals (Elliot et al., 1996, DFGLS) Phillips and Perron (1988, PP), and Ng and Perron (2001, NP) unit root tests, the null of a unit root is overwhelmingly rejected, for SS. However, for GT, while all the tests support that the variable is trend-stationary, the ADF and DF-GLStest tends to suggest non-stationarity of the series when the unit root test-equation has only a constant (or neither a constant and trend in case of the ADF test). The PP and the NP tests, though, indicate stationarity even under the assumption of constant only (and neither a constant and trend in case of the PP test). At this stage, it is important to highlight two issues: First, among the unit root tests conducted, the NP test is believed to have overwhelmingly stronger power relative to the other tests (Neely and Rapach, 2008; Das et al., 2014 and references cited therein), and hence, one would tend to rely on the results from this test. And second, given the nature of GT, it is evident that the unit root equation should in fact include a trend. Hence, taking these two points into account and all the above evidence we could conclude by saying that the global temperature is $\mathrm{I}(0)$, and first difference of global temperatures, would mean over-differencing the 
data and could lead to spurious conclusions, since we will now be looking at the causality between changes in global temperatures and sunspots and not global temperatures per se. Regarding a discussion of over-differencing leading to incorrect inferences (Plosser and Schwert (1978), Nelson and King (1984), Davis and Dunsmuir (1996), Hurvich and Chen (2000) amongst others). Thus, we do not need to transform the data further for either GT or SS. In addition, we do not need to account for cointegration between the two variables.

Table 1: Unit Root Test Results

\begin{tabular}{|c|c|c|c|c|c|c|c|}
\hline & \multicolumn{2}{|c|}{ None } & \multicolumn{2}{|c|}{ Intercept } & \multicolumn{2}{|c|}{ Intercept and Trend } \\
\hline & & Level & Decision & Level & Decision & Level & Decision \\
\hline \multirow{5}{*}{ GT } & $\mathrm{ADF}$ & $-1.620(17)$ & $\mathrm{I}(1)$ & $-1.598(17)$ & $\mathrm{I}(1)$ & $-3.707^{* * *}(24)$ & $\mathrm{I}(0)$ \\
\hline & PP & $-6.231^{* * *}(12)$ & $\mathrm{I}(0)$ & $-6.222^{* * *}(12)$ & $\mathrm{I}(0)$ & $-18.761^{* * *}(23)$ & $\mathrm{I}(0)$ \\
\hline & DF-GLS & ------------ & & $-1.539(6)$ & $\mathrm{I}(1)$ & $-3.037^{* *}(24)$ & $\mathrm{I}(0)$ \\
\hline & $\mathrm{Ng}-$ & & & & & & \\
\hline & Perron & ------------ & & $-10723.4^{* * *}(31)$ & $\mathrm{I}(0)$ & $-11688.3^{* * *}(12)$ & $\mathrm{I}(0)$ \\
\hline \multirow{5}{*}{ SS } & $\mathrm{ADF}$ & $-3.918^{* * * *}(24)$ & $\mathrm{I}(0)$ & $-6.984^{* * * *}(24)$ & $\mathrm{I}(0)$ & $-7.241^{* * * *}(24)$ & $\mathrm{I}(0)$ \\
\hline & PP & $-3.457^{* * *}(13)$ & $\mathrm{I}(0)$ & $-6.488^{* * *}(12)$ & $\mathrm{I}(0)$ & $-6.800^{* * *}(13)$ & $\mathrm{I}(0)$ \\
\hline & DF-GLS & ------------ & & $-5.396^{* * *}(24)$ & $\mathrm{I}(0)$ & $-7.075^{* * *}(24)$ & $\mathrm{I}(0)$ \\
\hline & $\mathrm{Ng}-$ & & & & & & \\
\hline & Perron & ----------- & $\mathrm{I}(0)$ & $-11476.7^{* * * *}(33)$ & $\mathrm{I}(0)$ & $-15395.3^{* * *}(32)$ & $\mathrm{I}(0)$ \\
\hline
\end{tabular}

Notes: ${ }^{*},{ }^{* *}$ and ${ }^{* * *}$ indicates significance at the $10 \%, 5 \%$ and $1 \%$ level, respectively. The critical values are as follows:

- $\quad$ None: $-2.566,-1.941$ and -1.616 for $\mathrm{ADF}$ and $\mathrm{PP}$ at $1 \%, 5 \%$ and $10 \%$ level of significance, respectively.

- Intercept: $-3.434,-2.863$ and $-2.567(-2.566,1.941,1.617)[-13.8,-8.1$ and -5.7$]$ for ADF and PP (DF-GLS) $[\mathrm{NP}]$ at $1 \%, 5 \%$ and $10 \%$ level of significance, respectively.

- $\quad$ Intercept and Trend: -3.963, -3.412 and -3.128 (3.48, 2.89, 2.57) [-23.80, -17.3 and -14.2] for ADF and PP (DFGLS) $[\mathrm{NP}]$ at $1 \%, 5 \%$ and $10 \%$ level of significance, respectively.

Numbers in parentheses for ADF, PP and DF-GLS tests indicates lag-lengths selected based on the Schwarz Information Criterion (SIC). For the NP test, based on the Barlett kernel spectral estimation method, the corresponding numbers are the Newey-West bandwith. 
Table 2. Time-Domain Granger Causality Test Results

\begin{tabular}{|c|c|c|}
\hline Sample & $\chi^{2}$ Test Statistic & $p$-value \\
\hline $1880: 1-2013: 9$ & $8.2850[4]$ & 0.0817 \\
\hline $1880: 1-1936: 2$ & $5.4526[4]$ & 0.2439 \\
\hline $1936: 3-1986: 11$ & $2.7488[3]$ & 0.4320 \\
\hline $1986: 12-2013: 9$ & $4.2603[4]$ & 0.3719 \\
\hline
\end{tabular}

Notes: $\mathrm{H}_{0}$ : Sunspot Numbers (SS) does not Cause Global Temperatures (GT). Numbers in brackets indicate the optimal number of lags chosen for the VAR, for each specific sample, based on Schwarz information criterion (SIC).

Though our primary interest is to analyze causality in the frequency domain to provide information on both short and long-run causalities, we also investigate Granger causality in the time domain for the sake of comparison. As can be seen from Table 2, the null hypothesis that SS does not cause GT can only be rejected at the 10 percent level of significance, but not at the conventionally used 5 percent level. Note that, the optimal lag-length for the VAR is 4 , based on the Schwarz information criterion (SIC). ${ }^{4}$

One of the key assumptions of Granger causality tests, both in time and frequency-domains, is that of parameter stability, i.e., the parameters in equations relating the variables, do not change over the sample under consideration. Given that we use a long-span of data covering from 1880 to 2013, the relationship between the two variables is likely to encounter structural breaks, and hence, one cannot rely on the results from full-sample causality (see for example Balcilar et al., 2010; Arslanturk et al., 2011; Balcilar and Ozdemir, 2013 and references cited there in for further details). In other words, causality tests needs to be carried out for sub-samples, since full-sample causality based on the assumption of parameter stability over the full-sample is likely to be spurious. In light of this, we perform the Bai and Perron (2003) sequential and repartition tests on the GT equation which involves a constant and 4 lags each of GT and SS, to check for possible structural breaks. We

\footnotetext{
${ }^{4}$ We also carried out impulse response analysis for the full-sample on a VAR(4), with the shocks being identified by the standard Choleski decomposition, whereby SS was, understandably, orderedfirst. The results revealed that though a shock to SS leads to an increase in GT, the effect is onlysignificant for the three-months-ahead horizon.
} 
detect two breaks at 1936:3 and 1986:12. ${ }^{5}$ Given this, we carry out the time-domain Granger causality test over three sub-samples: 1880:1-1936:2, 1936:3-1986:11 and 1986:12-2013:9. Again, the lag-length for the VAR for each sub-sample is based on the SIC. At each of these sub-samples, the null that SS does not cause GT cannot be rejected even at the 10 percent level of significance. Overall, barring the full-sample, where we obtain mild evidence that SS cause GT, the causality between these two variables are overwhelmingly rejected for different sub-samples determined by the periods of structural breaks. But as discussed above, due to structural breaks, the full-sample causality results cannot be relied upon and one needs to draw inference regarding causality from the sub-samples. So, based on the sub-sample analysis, the time-domain Granger causality tests tends to suggest that the null of SS does not Granger cause GT cannot be statistically rejected.

Next, we analyze causality using the frequency domain test proposed by Breitung and Candelon (2006) for the full-sample and the three sub-samples in Figures 2 through 5, with the same lag-structure as used in the time domain Granger causality tests.The figures depict the test statistics (solid line) along with their 5 percent critical values (broken line) for all frequencies in the interval $(0, \pi)$, to assess the predictive content of SS for GT. For the full-sample (1880:1-2013:9), the null hypothesis of non-predictability is rejected for $\omega$ greater than 2.45 corresponding to a cycle length between 2 and 2.6 months. ${ }^{6}$ For sub-samples 1 (1880:1-1936:2) and 2 (1936:3-1986:11), however, the null of no predictability cannot be rejected for any frequency. But for the final sub-sample (1986:12-2013:9), the null hypothesis is rejected for $\omega$ between 0 and 0.61 implying a cycle length of 10.3 months and above. So, as in the time domain Granger causality tests for sub-samples 2 and 3, the frequency domain tests too fail to reject the null that SS has no predictability for GT for these two sub-samples. However, for the full-sample and the last sub-sample, the null hypothesis is rejected for certain frequencies. More specifically, for the full-sample, the null is rejected at higher frequencies (shorter cycle lengths), while for the last sub-sample, SS is found to cause GT at shorter

\footnotetext{
${ }^{5}$ The details of these tests are available upon request from the authors.

${ }^{6}$ Recall that, the frequency $(\omega)$ on the horizontal axis can be translated into a cycle or periodicity of $T$ months by $T=(2 \pi$ $/ \omega)$, where $T$ is the period.
} 
frequencies (longer cycle lengths). Our results highlight the importance of analyzing causality using the frequency domain test, which, unlike the time domain Granger causality test, allows us to decompose causality by different time horizons, and hence, could detect predictability at certain cycle lengths even when the time domain causality might fail to pick up any causality at conventional levels of significance. However, as outlined above, due to structural breaks, the fullsample causality results cannot be relied upon and one needs to draw inference regarding causality from the sub-samples. So, based on the sub-sample analysis, the frequency-domain Granger causality tests tends to suggest that there has been an emergence of causality running from SS to GT only recently, and that SS tends to have predictive content for GT at cycle length of 10.3 months and above.

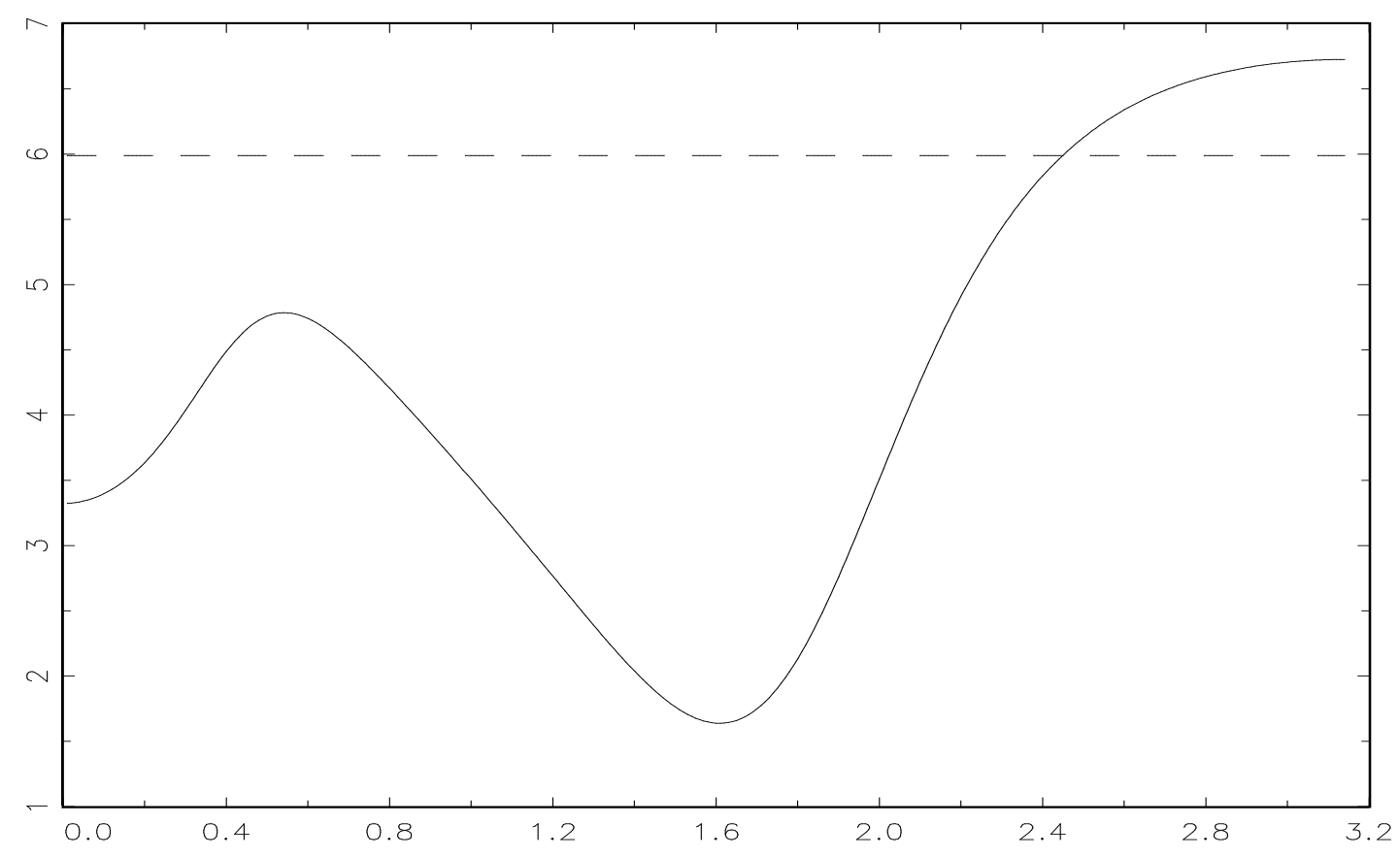

Figure 3: Frequency Domain Causality (1880:1-2013:9) 


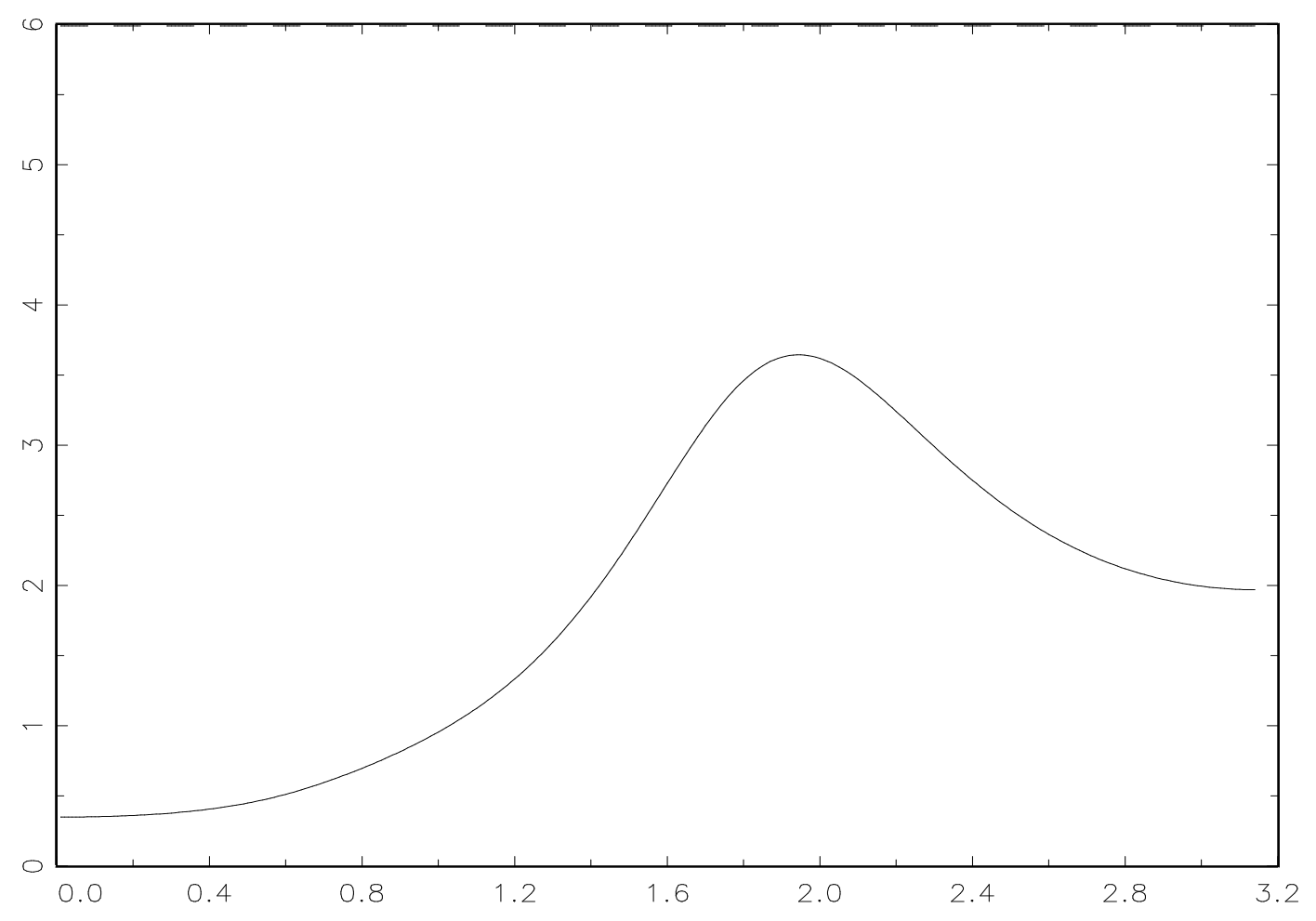

Figure 4: Frequency Domain Causality (1880:1-1936:2)

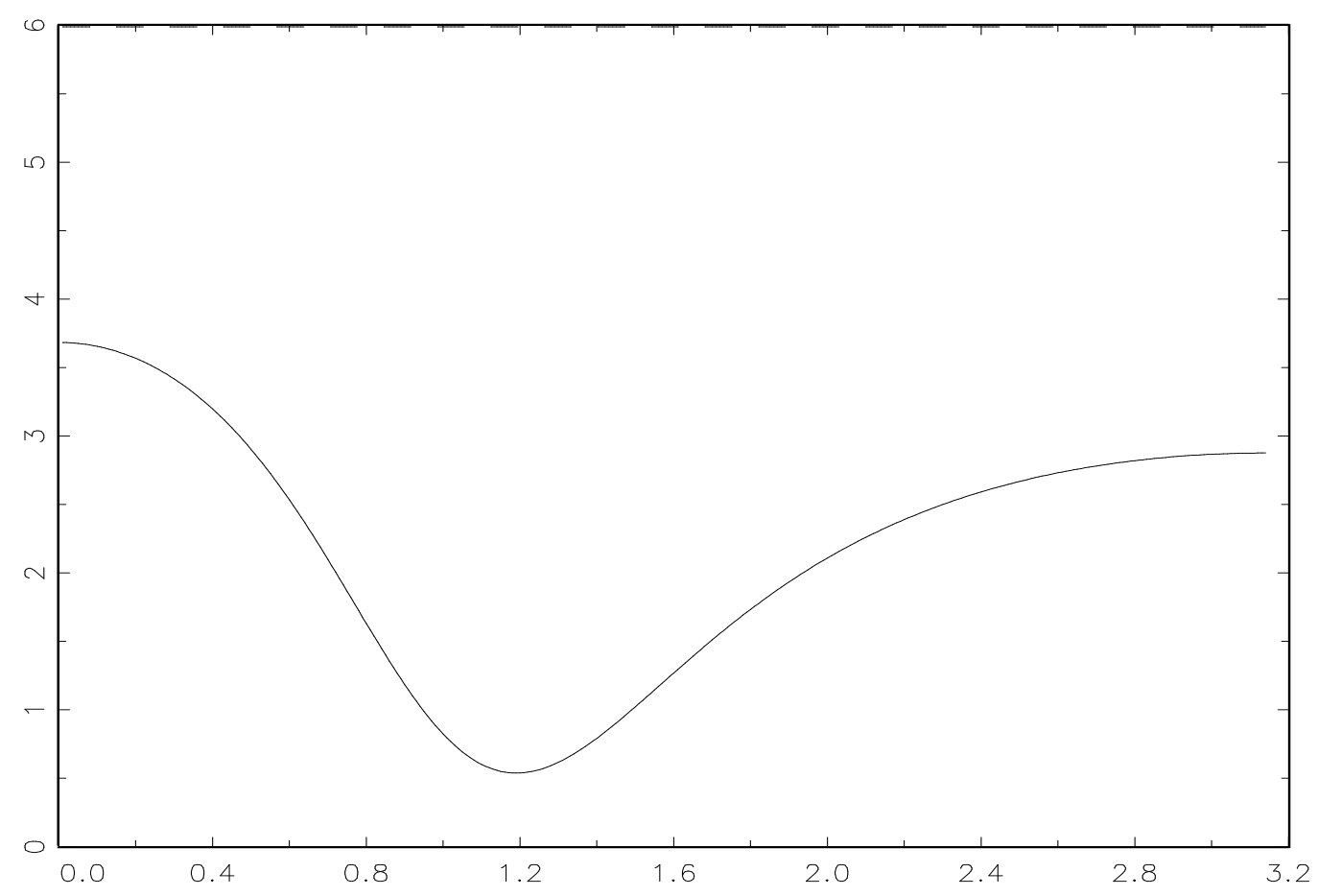

Figure 5: Frequency Domain Causality (1936:3-1986:11) 


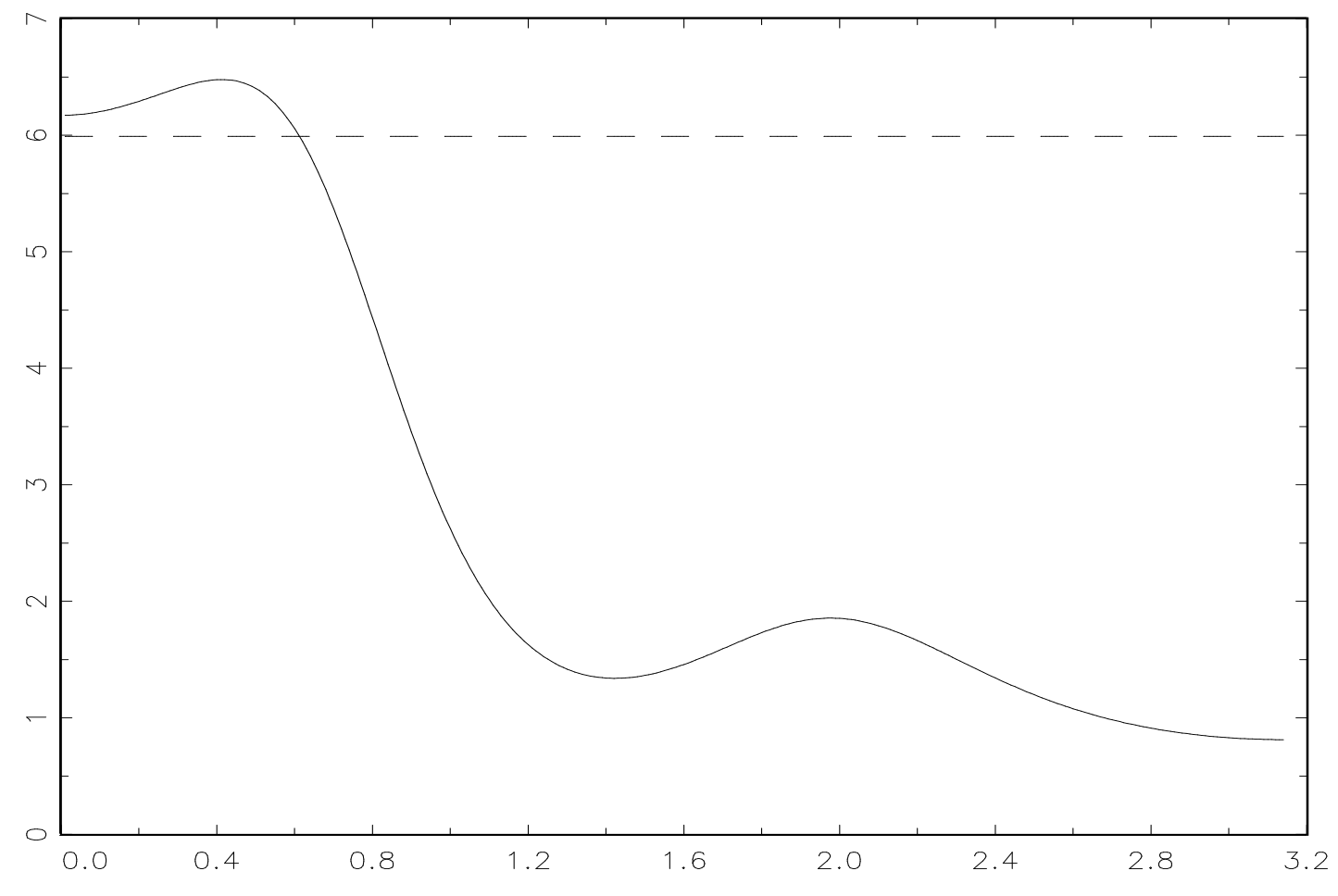

Figure 5: Frequency Domain Causality (1986:12-2013:9)

\section{Concluding remarks}

In this paper, we focus on the ability of sunspot numbers (used as a proxy for solar irradiance) to predict future global temperatures, and though the issue of the relationship between solar irradiance and climate has been widely examined, there is still no consensus about the nature of this relationship. Realizing that the relationship between sunspot numbers and global temperatures might vary across the frequency bands, a time domain analysis is likely to fail in fully capturing the link between these two variables. Against this backdrop, we apply the causality test in the frequency domain, developed by Breitung and Candelon (2006), to analyze whether sunspot numbers cause global temperatures, using monthly data covering 1880:1-2013:9. While, standard time domain Granger causality test fails to reject the null hypothesis that sunspot numbers does not cause global temperatures for both full and sub-samples (identified based on tests of structural breaks), the frequency domain causality detects predictability for both the full-sample and the last sub-sample at 
short (2 to 2.6 months) and long (10.3 months and above) cycle lengths respectively. Our results highlight the importance of analyzing causality using the frequency domain test, which, unlike the time domain Granger causality test, allows us to decompose causality at different frequencies, and hence, could detect predictability at certain cycle lengths even when the time domain causality test might fail to pick up any causality. However, as outlined above, due to structural breaks, the results for the full-sample causality, irrespective of whether it is in time or frequency domains, cannot be relied upon and one needs to draw inference regarding causality from the sub-samples. So, based on the sub-sample analysis, the frequency-domain Granger causality tests tends to suggest that there has been an emergence of causality running from SS to GT only recently, and that SS tends to have predictive content for GT at cycle length of 10.3 months and above. Given that, we identified structural breaks in the relationship between global temperatures and sunspot numbers (and hence, carried out the tests over sub-samples), as part of future research, it would be interesting to conduct time-varying causality (using for instance rolling causality in the time-domain or wavelet analysis in both time and frequency domains) to decipher the exact periods for which sunspot numbers have predictive ability for global temperatures.

Finally, we should note that the results obtained in this work should be taken with caution. First, sunspot number record is only a partial approximation to solar irradiance which is one of the variables of interest to analyze climate warming (Scafetta, 2014). Moreover, the global temperature patterns are not only determined by solar inputs as other factors such as volcano, anthropogenic and other natural oscillations might be driven Earth's climate. Finally, the relationship between solar forces and global temperatures might have a nonlinear nature. Scafetta (2014) found solar and climatic indexes to be related to each other through complex and non-linear processes, with his work being a reply to Gil-Alana, et al., (2014), who were of the opinion that these variables are not related. Clearly, then the relationship between these two variables are not completely resolved and should 
incorporate further econometric details in terms of additional variables and nonlinearity, something we leave for future research.

\section{References}

Aguirre, L.A., Letellier, C. and Maquet, J. (2008), Forecasting the time series of sunspot numbers, Solar Physics 249, 103-120.

Ambelu T., Falayi E.O., Elemo, E., and O. Oladosu, (2011), Estimation of total solar irradiance from sunspot number, Latin American Journal of Physics Education 5, 4.

Arouni, M., Tiwari, A.K. and Teulon, F. (2014). Oil prices and trade balance: A frequency domain causality analysis for India. Working Paper Series, IPAG Business School, Paris, France.

Arslanturk, Y., Balcilar, M. and Ozdemir, Z.A. (2011).Time-varying linkages between tourism receipts and economic growth in a small open economy.Economic Modelling, 28, 664-671.

Ashley, R.A. and Verbrugge, R.J. (2009). Frequency dependence in regression model coefficients: An alternative approach for modelling nonlinear dynamic relationships in time series. Econometric Reviews, 28, 4-20.

Ashley, R.A. and Ye, H. (2012). On the Granger causality between median inflation and price dispersion. Applied Economics, 44: 4221-4238.

Aslanoglu, E. and Deniz, P. (2012). How does stability in financial openness affect growth. Topics in Middle Eastern and African Economies, 14, 164-189.

Assenmacher-Wesche, K., Gerlach, S., and Sekine, T. (2008), "Monetary factors and inflation in Japan", Journal of Japanese International Economies, 22(3), 343-363.

Auerbach, R.D. and Rutner, J.L. (1976). Time and frequency domain tests of some U.S. - Canadian relationships under an autoregressive filter. Applied Economics 8, 165-178.

Bai, J. and Perron, P. (2003).Computation and analysis of multiple structural change models, Journal of Applied Econometrics, 18, 1-22.

Balcilar, M. andOzdemir, Z.A.(2013).The export-output growth nexus in Japan: a bootstrap rolling window approach.Empirical Economics, 44, 639-660.

Balcilar, M., Ozdemir, Z.A. and Arslanturk, Y. (2010).Economic growth and energy consumption causal nexus viewed through a bootstrap rolling window. Energy Economics, 32, 1398-1410,

Bentzen, J., 2007, Does OPEC influence crude oil prices? Testing for co-movements and causality between regional crude oil prices, Applied Economics, vol. 39, pp. 1375-1385. 
Bodart, V., and Candelon, B. (2009). Evidence of interdependence and contagion using a frequency domain framework.Emerging Markets Review, 10(2), 140-150.

Breitung, J. and Candelon, B. (2006).Testing for short- and long-run causality: A frequency-domain approach. Journal of Econometrics 132, 363-378.

Ciner, C. (2011a). Eurocurrency interest rate linkages: A frequency domain analysis. International Review of Economics and Finance, 20(4), 498-505.

Ciner, C. (2011b). Commodity prices and inflation: Testing in the frequency domain", Research in International Business and Finance, 25(3), 229-237.

Das, S., Gupta, R., Kanda, P.T., Reid, M., Tipoy, C.K. and Zerihun, M.F. (2014). Real interest rate persistence in South Africa: evidence and implications. Economic Change and Restructuring, 47, 4162.

Davis, R.A. and W.T.M. Dunsmuir (!996) Maximum likelihood estimation of MA(1) processes with a unit root on or near the unit root circle, Econometric Theory 12, 1-29.

Dickey, D. and Fuller, W. (1981). Likelihood ratio statistics for autoregressive time series with a unit root. Econometrica, 49, 1057-1072.

Dropsy, V. (1996). Macroeconomic determinants of exchange rates: a frequency-specific analysis. Applied Economics 28, 55-63.

Dufour, J.M., Renault, E., 1998. Short run and long run causality in time series: theory. Econometrica 66, 1099-1125.

Dufour, J.M., Renault, E., 2006. Short run and long run causality in time series: inference. Journal of Econometrics 132, 2, 337-362.

Eichler, A., Olivier, S. Heenderson, K., Laube, A., Beer, J., Papina, T., Gaggeler, H.W. and Schwikowski, M., (2009). Temperature response in the Altai region lags solar forcing, Geophysical Research Letters 36, 1.

Elliot, G., Rothenberg, T.J. and Stock, J.H. 1996. Efficient tests for an autoregressive unit root. Econometrica, 64, 813-836.

Erol, U. and Balkan, E. (1991). The reaction of stock returns to anticipated and unanticipated changes in money: a re-examination of the evidence in the frequency domain. Applied Economics $23,113-122$.

Folland, C.K., Colman, A.W., Smith, D.W., Boucher, O., Parker, D.E. and Vernier, J-P.(2013). High predictive skill of global surface temperature a year head.Geophysical Research Letters, 40(4), 761767.

Friis-Christensen, E. and Lassen, K.(1991). Length of the solar cycle, an indication of solar activity closely associated with climate. Science, 254, 698-700. 
Gelper, S., Lemmens, A. and Croux, C. (2007). Consumer sentiment and consumer spending: decomposing the Granger causal relationship in the time domain. Applied Economics 39, 1-11.

Geweke, J., (1982). Measurement of linear dependence and feedback between multiple time series.Journalof the American Statistical Association 77, 304-324.

Gil-Alana, L. A., 2003. Unemployment and real oil prices in Australia: a fractionally cointegrated approach, Applied Economics Letters, vol. 10, pp. 201-204.

Gradojevic, N. (2013). Causality between regional stock markets: A frequency domain approach. Panoeconomicus, 5, 633-647.

Grandojevic, N. and Dobardzic, E. (2013). Causality between regional stock markets: A frequency domain approach. Panoeconomicus, 5, 633-647.

Granger C.W.J. (1969).Investigating causal relations by econometric models and cross-spectral methods. Econometrica 37, 424-439

Gray, L.J., Beer, J., Geller, M., Haigh, J.D., Lockwood, M., Matthes, K., Cubasch, U., Fleitmann, D., Harrison, G., Hood, L., Luterbacher, J., Meehl, G.A., Shindell, D., van Geel, B. and White, W. (2010), Solar influences on climate, Review of Geophysics 48, 4.

DOI: 10.1029/2009RG000282.

Gronwald, M. (2009).Reconsidering the macroeconomics of oil price in Germany: Testing for causality in the frequency domain. Empirical Economics, 36(2), 441-453.

Hosoya, Y. (1991). The decomposition and measurement of the interdependence between secondorderstationary process. Probability Theory and Related Fields 88, 429-444.

Hoyt, D.V. and K.H. Schatten (1997), The role of the sun in the climate change, Oxford University Press, New York.

Hurvich, C.M. and W.W. Chen (2000), An efficient taper for potentially overdifferenced long memory time series, Journal of Time Series Analysis 21, 155-180.

Ineson, S., A.A. Scaife, J.R. Knight, J.C. Manners, J.J. Dunstone, L.J. Gray, and J.D. Haigh (2011).Solar forcing of winter climate variability in the Northern Hemisphere. Nature Geoscience 4, 753-757.

Jones, J.D. and Uri, N. (1987). Money, Inflation and Casuality (Another Look at the Empirical Evidence for the USA, 1953-84). Applied Economics 19, 619-634.

Lean, J.L. and Rind, D.H. (1998).Climate forcing by changing solar radiation, Journal of Climate 11, 12, 3069-3094.

Lean, J.L. and Rind, D.H. (2009). How will earth's surface temperature change in future decades?, Geophysical Research Letters 36, 15.DOI: 10.1029/2009GL038932. 
Lee, J. and Strazicich, C. M. (2003). Minimum Lagrange Multiplier Unit Root Test with Two Structural Breaks. The Review of Economics and Statistics, 85, 1082-89.

Love, J.J., Mursula, K., Tsai, V.C. and Perkins, D.M. (2011). Are secular correlations between sunspots, geomagnetic activity, and global temperature significant? Geophysic Research Letters 38, $1-6$.

Lumsdaine, R. and Papell, D. (1997). Multiple Trend Breaks and the Unit Root Hypothesis. Review of Economics and Statistics 79, 212-218.

Nachane, D. and Dubey, A.K. (2013). Trend and cyclical decoupling: new estimates based on spectral causality tests and wavelet correlations. Applied Economics, 45, 4419-4428.

Neely, C. J. and Rapach D. E. (2008). Real Interest Rate Persistence: Evidence and Implications.

Federal Reserve Bank of St. Louis Review, 90, 609-41.

$\mathrm{Ng}$, S. and Perron, P. (2001). Lag length selection and the construction of unit root tests with good size and power. Econometrica, 69, 1519-1554.

Phillips, P.C.B. and Perron, P. (1988).Testing for a unit root in time series regression, Biometrika 75, 335-346.

Pittock, B. (1978). A critical look at long term sum-weather relationships. Review of Geophysics and Space Physics 16(3), 400-420.

Pittock, B. (1983). Solar variability, weather and climate: an update. Quarterly Journal of the Royal Meteorological Society 109, 23-55.

Pittock, B. (2009). Can solar variations explain variations in Earth's climate? Climate Change 96, 483-487.

Preminger, D. G. and S.A. Walton, (2005), A new model of total solar irradiance based on sunspot areas, Geophys. Res. Lett. 32, 1-5, L14109, doi: 10.1029/2005GL022839.

Scafetta, N. (2009). Empirical analysis of the solar contribution to global mean air surface temperature change. Journal of Atmospheric and Solar-Terrestrial Physics 71, 1916-1923.

Scafetta, N. (2011). A shared frequency set between the historical mid-latitude aurora records and the global surface temperature. Journal of Atmospheric and Solar-Terrestrial Physics, 102, 368-371.

Scafetta, N. (2014). Global temperatures and sunspot numbers. Are they related? Yes, but non linearly. A reply to Gil-Alana et al. (2014). Physica A 413, 329-342

Scafetta N., Grigolini, P.Imholt, T., Roberts, J.A. and West, B.J. (2004).Solar turbulence in earth's global and regional temperature anomalies. Physical Review E 69, 026303.

Scafetta, N., and West, B.J. (2003).Solar flare intermittency and the earth temperature anomalies, Physical Review Letters, 90, 248701. 
Scafetta, N. and West, B.J. (2005).Estimated solar contribution to the global surface warming using the ACRIM TSI satellite composite. Geophysical Research Letters 32, L18713.

Scaffeta, N. and R. Willson (2009), ACRIM-gap and Total Solar Irradiance (TSI) trend issue resolved using a surface magnetic flux TSI proxy model, Geophysical Research Letters 36.

Scafetta, N. and R. Willson (2014), ACRIM total solar irradiance satellite compostite validation versus TSI proxy models, Astrophysics and Space Science, forthcoming.

Schreiber, S. (2009).Low-frequency determinants of inflation in the euro area.Working Paper 6/2009, Macroeconomic Policy Institute.

Shindell, D.T., Schmidt, G.A., Mann, M.E., Rind, D. and Waple, A. (2001).Solar forcing of regional climate change during the Maunder Minimum.Science294, 2149-2152.

Soon, W.W.H. (2009), Solar artic mediated climate variation on multidecadal to centennial timescales: empirical evidence, mechanistic explanation and testable consequences, Physical Geography 30, 2, 144-148.

Sun, L. and Wang, M. (1996). Global warming and global dioxide emission.: An empirical study. Journal of Environmental Management, 46 (4): 327-343.

Tari, R. and Abasiz, T. (2009). Frequency domain approach and short run and long run causality test: Evidence from Turkey for interest rate and exchange rate relationship. Mutu Studies in Development, 36 (2),

Usoskin, I.G., Schussler, M., Solanki, S.K. and Mursula, K. (2004).Solar activity over the last 1150 years. Does it correlate with climate? Proceedings of $13^{\text {th }}$ Cool Stars Workshop, Hamburg.

Vaquero, J. M., Gallago, M. C., Trigo, R. M., Sanchez, F., Cancillo, M. L. and Garcia, J. A., (2006) A new reconstruction of total solar irradiance since 1832, Atmosfera19, 267-274.

Wei, Y.F. (2013a). Commodity prices, manufactured goods prices and inflation: Evidence from Japan. Economics Bulletin, 33(2), 986-992.

Wei, Y.F. (2013b). The dynamic relationship between oil prices and the Japanese economy: A frequency domain analysis. Review of Economics and Finance, 3(2),57-67.

Willson, R. C. (1997). Total solar irradiance trend during solar cycles 21 and 22. Science, 277: 19631965.

Yao, F. and Hosoya, Y. (2000).Inference on one-way effect and evidence in Japanese macroeconomic data.Journal of Econometrics 98, 225-255.

Yanfeng, W. (2-12). The dynamic relationship between oil prices and the Japanese economy: A frequency domain analysis. Review of Economics and Finance, 2, 57-67.

Zhou, J. and Tung, K-K. (2013). Deducing Multidecadal Anthropogenic Global Warming Trends Using Multiple Regression Analysis. Journal of Atmospheric Science 70, 3-8. 
Zivot, E. and Andrews, W. (1992). Further Evidence on the Great Crash, the Oil Price Shock and the Unit Root Hypothesis.Journal of Business and Economic Statistics, 10, 251-70. 